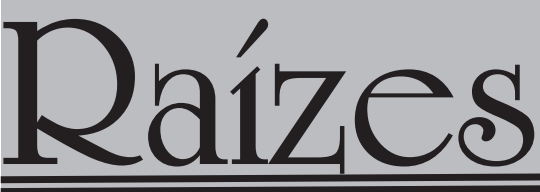

v.32, n.1, jan-jun / 2012

\title{
O SINDICALISMO NA AGRICULTURA FAMILIAR E A CONSTRUÇÃO DA PAUTA AMBIENTAL NO SUL DO BRASIL
}

\author{
Everton Lazzaretti Picolotto*
}

\begin{abstract}
RESUMO
As preocupações ambientais têm influenciados os projetos políticos e a construção das pautas das organizações de agricultores familiares. O objetivo deste artigo é analisar como estas preocupações têm sido assimiladas pela Federação dos Trabalhadores na Agricultura Familiar da Região Sul (FETRAF-Sul). Com base em pesquisa documental e entrevistas com lideranças de agricultores, fez-se uma leitura sobre o processo de construção da pauta ambiental no sindicalismo rural a qual indica que desde meados da década de 1980 o tema ambiental vem se fazendo presente na atuação sindical e que a forma como ele vem sendo entendido muda ao logo dos anos. Se em um primeiro momento tendia a ser associado com as consequências negativas da modernização da agricultura, no período mais recente o tema ambiental vem sendo colocado no centro do projeto de agricultura do sindicalismo rural e passa a fomentar a positivação do modelo de produção da agricultura familiar.
\end{abstract}

Palavras-chaves: Agricultura Familiar, Sindicalismo, Pauta Ambiental, Agroecologia, FETRAF-Sul.

\section{SYNDICALISM IN FAMILY FARMING AND THE CONSTRUCTION OF THE ENVIRONMENTAL AGENDA IN SOUTHERN BRAZIL}

\begin{abstract}
Environmental concerns have influenced the construction of political projects and agendas of organizations of family farmers. The aim of this paper is to analyze how these concerns have been assimilated by the Federation of Workers in Family Farming in the South Brazil (South-FETRAF). Based on archival research and interviews with leaders of farmers we present here an interpretation on the process of building of the environmental agenda in rural syndicalism according to which since the mid-1980s the environmental issues have appeared in the syndicate action. We also observed that the ways by which they have been understood have changed over the years. If at first they tended to be associated with the negative consequences of modernization of agriculture, more recently they have been placed in the center of the syndicalism farming project, fostering a positive view on the family farming mode of production.
\end{abstract}

Key words: Family Farms, Rural Syndicates, Environmental Agenda, Agroecology, FETRAF.

*Everton Lazzaretti Picolotto. Professor Adjunto do Departamento de Ciências Sociais da Universidade Federal de Santa Maria. Pós-Doutorado na Universidade Federal do Paraná. Bolsista do CNPq. E-mail. evpicolotto@yahoo.com.br 
INTRODUÇÃO

As preocupações ambientais do período contemporâneo têm influenciado organizações de representação de agricultores familiares a incluírem em seus projetos a perspectiva de apoio a formas e técnicas de produção causadoras de menores impactos ambientais, resgate de práticas de produção e de conhecimentos tradicionais, diversificação produtiva, práticas de agricultura sob preceitos agroecológicos, entre outras. A Federação dos Trabalhadores na Agricultura Familiar da região Sul (FETRAF-Sul), herdeira do sindicalismo rural da Central Única dos Trabalhadores (CUT), é um dos atores que, desde a sua origem, na década de 1980, tem procurado incluir em seu projeto político estas preocupações, ao passo que também tem estimulado e orientado ações práticas desse formato de agricultura entre agricultores.

Para promover novas práticas produtivas, tem sido importante a assessoria de organizações não governamentais (ONGs) que vêm construindo críticas aos efeitos perversos do processo de modernização da agricultura, promovido no Brasil desde a década de 1960. A construção da pauta ecológica parte de um diagnóstico sobre as consequências negativas da modernização sob vários ângulos: as ambientais, com a destruição de recursos naturais, a erosão de solos, a contaminação de águas, etc.; as socioeconômicas, com o êxodo rural, o empobrecimento e a exclusão dos pequenos agricultores do processo produtivo; e as culturais, com a perda dos conhecimentos tradicionais, do saber fazer e da etnobiodiversidade (DIEGUES, 2000). Da constatação dos efeitos negativos da modernização surgiram propostas de recuperar formas de produzir e de relação com a natureza do passado dos agricultores, buscan- do nelas embasamentos para constituir novas formas de produzir, mais harmônicas com a natureza.

Essa tentativa de resgate de técnicas de produção e formas de relação com a natureza do passado foi buscada, na região Sul, em especial nas práticas de um grupo específico de agricultores, os chamados colonos, que formam a maior parte da base social da FETRAF-Sul (PICOLOTTO, 2011). Os colonos são entendidos como os descendentes de imigrantes europeus (alemães, italianos, poloneses, entre outros) que formaram colônias a partir de meados do século XIX e início do XX nas regiões de matas não apropriadas pelas grandes explorações. Nessas regiões, desenvolveu-se a pequena propriedade e um formato de exploração agropecuária diversificada, dedicada à subsistência familiar e ao comércio de alguns produtos agropecuários (ROCHE, 1969).

Com o processo de modernização da agricultura promovido pelo Estado nas décadas de 1960-70, os colonos foram incentivados a abandonar as formas tradicionais de produção, a adotar novas técnicas, consideradas mais modernas e eficientes, e acabaram se especializando na produção de poucas culturas e criações (como soja, trigo, uva, suínos, frangos, entre outras). Com a crise econômica do final da década de 1970 e início da de 1980, que atingiu fortemente a agricultura, muitos destes colonos que haviam seguido as orientações do Estado (mesmo que parcialmente) enfrentaram grandes dificuldades para se manter na atividade, e muitos foram obrigados a migrar para as cidades ou a entrarem na luta por terra (BRUM, 1988).

Foi neste contexto de desgaste do modelo de produção agrícola considerado moderno, de construção de oposição às grandes 
obras realizadas em nome do desenvolvimento nacional (barragens, estradas etc.), de crise do regime militar, do processo de abertura política e redemocratização do país consolidado com a Constituição de 1988 e de realização da II Conferência Mundial sobre Meio Ambiente e Desenvolvimento no Brasil (Eco-92) em 1992, que foram propiciadas as "oportunidades políticas"1 (TARROW, 2009) para se constituir, no país, diversos novos atores questionadores da situação vigente. Dentre eles, o movimento ambientalista e a emergência da pauta ambiental (ALONSO; COSTA; MACIEL, 2007).

Acompanhando estes processos mais amplos e visando gerar respostas às necessidades dos pequenos agricultores, surgiram iniciativas de diversificação da produção, tecnologias alternativas, experiências de agricultura de base ecológica, uso de sementes e insumos próprios, dentre outros. Surgiam como uma forma de reação às consequências negativas de modernização da agricultura e como forma de encontrar novos caminhos para os pequenos agricultores. Algumas formas de desenvolver práticas agrícolas de maneiras mais autônomas e harmoniosas com a natureza puderam ser buscadas nas suas experiências do passado, do período anterior à modernização da agri- cultura. Aparentemente, a partir de uma síntese entre o resgate de práticas antigas, novas preocupações com o ambiente e conhecimentos técnico-científicos, foram formadas as bases do que se chamou de agricultura alternativa ou tecnologias alternativas, na década de 1980, e vêm sendo associadas, no período mais recente, à agricultura ecológica (também chamada pelas organizações de agricultores de agricultura orgânica ou agroecológica²).

Nessa forma de entender, as experiências de tecnologias alternativas e de agricultura ecológica dos agricultores no Sul do Brasil, na medida em que foram buscar formas de produzir do passado dos colonos e são pensadas a partir das dificuldades enfrentadas no período contemporâneo, podem ser lidas como formas de reinterpretar ou dar novos sentidos às formas tradicionais de produzir do grupo social, atualizando-as positivamente. Ao resgatar práticas do passado, ressignificadas com questões do tempo presente (preocupações ambientais), os agricultores buscaram alcançar um espaço na sociedade atual para os pequenos agricultores (ou agricultores familiares, como passaram a ser chamados a partir da década de 1990) e pensar, a partir de sua "experiência" enquanto grupo social (THOMPSON, 1987) ${ }^{3}$, um novo modelo

\footnotetext{
1. Para Tarrow (2009, p.99) as oportunidades políticas aparecem nos momentos em que sujeitos ou grupos sociais "recebem recursos externos para escapar da submissão" a que são submetidos e nas ocasiões em que se sentem "ameaçados por custos que não podem arcar ou que ofendem seu senso de justiça". Mas também, as oportunidades políticas "fornecem informações cruciais para a formação dos movimentos quando revelam aliados e expõem a fraqueza do inimigo.” (id. p.100). 2. Nesse texto, não se tem objetivo de entrar na discussão sobre as diferenças conceituais entre os termos tecnologias alternativas, agricultura orgânica, agricultura ecológica e agroecologia. Ressalta-se apenas que enquanto a agroecologia, sob o ponto de vista acadêmico, deve ser entendida como um enfoque científico destinado a apoiar a transição dos atuais modelos de desenvolvimento rural e de agricultura convencionais para estilos de desenvolvimento rural e de agricultura sustentáveis (SEVILLA GUZMÁN 2000; CAPORAL E COSTABEBER, 2000), para as organizações de agricultores os sentidos atribuídos ao termo agroecologia ou agricultura ecológica (usados em sentidos semelhantes) normalmente são mais amplos e aplicados às suas próprias experiências e práticas de agricultura que rompem, em alguma medida, com os modelos convencionais (BARCELLOS, 2009; PICCIN, 2007). Durante o trabalho chamase atenção para os usos que as organizações de agricultores fazem do termo agroecologia e outros que usam em sentidos próximos. 3. Para Thompson (1981, p.188-189), a "experiência" de uma classe ou grupo social é formada pelos "sistemas densos, complexos e elaborados pelos quais a vida familiar é estruturada e a consciência social encontra realização e expressão [...]: parentesco, costume, as regras visíveis da regulação social, hegemonia e dependência, formas simbólicas de dominação e da resistência, fé religiosa e impulsos milenaristas, maneiras, leis, instituições e ideologias - tudo o que em sua totalidade, compreende a 'genética' de todo o processo histórico, sistemas que se reúnem todos, num certo ponto, na experiência humana comum, que exerce ela própria (como experiências de classe particulares) sua pressão sobre o conjunto.”
} 
de agricultura com menores impactos no ambiente.

Da confluência entre a experiência social e produtiva do grupo e as preocupações ambientais contemporâneas, constituíram-se articulações entre organizações de representação (como a FETRAF/CUT), setores da Igreja Católica e Luterana e ONGs que buscavam formas de reinserir os colonos na sociedade nacional, ao mesmo tempo em que se preocupavam com as questões ambientais. Como a FETRAF é herdeira destes processos, nos seus documentos a agricultura familiar é apresentada como o setor social que pode constituir uma relação mais harmoniosa entre homem e natureza, produzir alimentos diversificados e com qualidade para o povo brasileiro e conjugar as intenções de desenvolvimento agrícola com o respeito à natureza e às culturas locais (FETRAF-Sul, 2002; 2007; 2010). Para a FETRAF, o agricultor familiar passa a ser o personagem que pode consolidar um novo modelo de desenvolvimento para a agropecuária brasileira, cujas preocupações com inclusão social, desenvolvimento agrícola e preservação das culturas locais e do ambiente constituem eixos centrais.

Este artigo visa refletir sobre como a pauta ambiental foi internalizada pelo sindicalismo da FETRAF no Sul do país. Na realização dos investimentos de pesquisa que deram base para este artigo, fez-se uso de consulta a documentos produzidos pelas organizações de agricultores familiares e suas assessorias, entrevistas com lideranças de agricultores e assessores, participação em eventos da Federação, além de consulta à bibliografia já existente sobre o tema.

\section{CRÍTICA À MODERNIZAÇÃO DA AGRI-}

\section{CULTURA E FORMAÇÃO DE UMA REDE AGROAMBIENTALISTA}

Na década de 1970, ocorreram profundas transformações no meio rural brasileiro, conduzidas centralmente pela ação estatal. Dentre as principais transformações estruturais ocorridas na década de 1970, Gonçalves Neto $(1997$, p.141) destaca o rápido processo de urbanização que transformou o país de rural em urbano; o crescimento acentuado do comércio exterior; a alteração da base técnica da produção rural, com ampla absorção de capital; e a definição de um sistema nacional de crédito e assistência técnica rural, que motivou e sustentou o processo de modernização do setor agrário. Como resultado deste processo, ainda de acordo com esse autor, ocorreu, de um lado, a "transformação da base técnica em boa parte do setor agrário, no que se convencionou chamar de modernização desigual" (id. p.224-225, grifos no original), privilegiando os grandes proprietários de terras; as culturas voltadas para o mercado externo; as regiões mais desenvolvidas do centro-sul e atingindo apenas uma parcela de agricultores que tiveram crédito subsidiado (em torno de 20 a 25\%). E, de outro lado, promoveu a formação dos complexos agroindustriais, constituídos por um conjunto de empresas de produção insumos modernos, máquinas, equipamentos, fertilizantes, defensivos, medicamentos veterinários, etc, situadas a montante do setor agropecuário; e empresas para compra, transformação e comercialização da produção agrícola, antes de atingir o consumidor, situadas a jusante do setor.

No Planalto Gaúcho, por exemplo, este processo de modernização promoveu grandes mudanças no modo de produzir e de viver dos 
agricultores, com destaque para a especialização produtiva (principalmente no binômio trigo-soja) e a modernização tecnológica das lavouras com o uso de maquinários, agroquímicos e sementes híbridas. Para impulsionar a modernização da agricultura, o principal vetor utilizado foi a política de "assistência creditícia" (BRUM, 1988). O Sistema Nacional de Crédito Rural $^{4}$, ao conceder crédito, subordinava o agricultor à fiscalização e à assistência técnica dos órgãos oficiais.

A política agrícola beneficiou, sobretudo, as culturas denominadas dinâmicas, aqueles produtos mais diretamente ligados à indústria e à exportação, em detrimento dos cultivos de subsistência. Muitas áreas destinadas ao cultivo de produtos alimentícios básicos foram substituídas por lavouras de monocultura, para o suprimento de agroindústrias ou do mercado externo. Este formato de agricultura passou a produzir, em grande escala, aquelas culturas cujos preços altos no mercado garantiam lucro certo em tais empreendimentos. O Estado estimulou esses setores competitivos, praticamente abandonando aquelas culturas que se têm constituído, historicamente, na alimentação básica dos brasileiros. Como afirmam Martine e Garcia (1987, p. 83): "O favorecimento de culturas 'dinâmicas' para exportação e/ou para as agroindústrias relegou a produção de gêneros de primeira necessidade, particularmente de feijão, mandioca e arroz, essenciais à sobrevivência dos estratos de renda mais baixa, a um status secundário".

Estas orientações produziram a especialização dos agricultores nas culturas consideras viáveis economicamente. A adoção destes culti- vos e dos pacotes tecnológicos a eles associados fez com que os agricultores experimentassem fortes mudanças nas formas de produzir e de viver:

Da enxada, do arado de tração animal e da carroça, passou-se ao trator, à automotriz, ao caminhão, ao automóvel etc. Rompeu-se o ritmo lento do meio rural marcado pela tradição. Aumentou a velocidade do sistema de produção, bem como dos contatos e das informações. A visão do mundo ampliou-se, abarcando não apenas o distrito ou o município, mas o Estado, o País, e o plano internacional (BRUM, 1988, p. 122).

O projeto de modernização técnica teve seu auge durante os anos 1970. Após um ciclo de crescimento (onde o PIB cresceu a uma taxa de $8,1 \%$, em média, entre 1965/80), a economia brasileira enfrentou uma dura crise recessiva a partir de 1981. O custo do endividamento exterior, somado à conjuntura desfavorável da economia mundial, levou a que, no início da década de 1980, se vivenciasse no Brasil uma conjuntura de crise generalizada em amplos setores. O setor agropecuário foi um dos mais atingidos (DELGADO, 2004).

Este processo de modernização passou a ser fortemente contestado a partir do final dos anos 1970, seja por agricultores dele excluídos e suas organizações de representação, seja por técnicos e estudiosos da questão agrária. Sindicatos, Igrejas, ONGs e Academia produziram críticas ao modelo de desenvolvimento autoritário, excludente e insustentável, constituído

4. O sistema de crédito foi criado em 1965, mas teve maior efetividade de atuação na década de 1970. 
pelas políticas de modernização da agricultura no período do regime militar (ALMEIDA, 1989; BRANDENBURG, 1999; SCHMITT, 2001; DIAS, 2004). O modelo de agricultura da modernização mostrava a sua face mais perversa para os agricultores de base familiar do Sul, na década de 1980. Schmitt (2002) destaca a situação insustentável e os impasses em que se encontravam: a especialização excessiva, a dependência em relação a insumos externos, a fraca integração entre os diferentes sistemas de cultivo e criação, a perda das variedades localmente adaptadas, a erosão do conhecimento sobre o manejo da biodiversidade local, a degradação da qualidade do solo e da água, e a crescente desvalorização das atividades e dos produtos destinados à subsistência das famílias agricultoras.

As ações de questionamento a esta situação também resultaram em iniciativas de construção de alternativas organizativas e formas de produzir para pensar novos horizontes para os pequenos produtores com dificuldades de manterem-se na atividade agrícola e pensar um novo modelo para o campo. Neste sentido, foram importantes as ações da Comissão Pastoral da Terra (CPT) na região Sul e um conjunto de ONGs que formaram a Rede de Tecnologias Alternativas/Sul (REDE TA/SUL, 1997; BRANDENBURG, 1999).

A Rede Tecnologias Alternativas/Sul (Rede TA/Sul) surgiu de uma articulação de ONGs ambientalistas que iniciaram a organização de um "movimento contestatório ao processo de modernização da agrícola" (REDE TA/ SUL, 1997, p. 177). A origem dessa articulação se deu com a criação do Projeto Tecnologias Alternativas (PTA) pela Federação de Órgãos para Assistência Social e Educação (FASE), em $1983^{5}$ . Em 1989, este Projeto deu base para a criação de uma organização independente, a Assessoria e Serviços a Projetos em Agricultura Alternativa (AS-PTA), realizando trabalhos nas regiões Sul, Sudeste e Nordeste do país. Especificamente na região Sul, se criou a Rede TA/Sul como "uma rede de entidades não governamentais, sem fins lucrativos e de caráter não partidário ou religioso, que desenvolve trabalhos de pesquisa, assessoria, formação e difusão na área de tecnologias alternativas para a agricultura." (REDE TA/SUL, 1997, p. 170). A rede foi formada por conjunto heterogêneo de organizações no três estados do Sul, tais como: a Fundação para o Desenvolvimento Econômico Rural da Região Centro-Oeste do Paraná (RURECO) e a Associação de Estudos Orientação e Assistência Rural (ASSESSOAR) no Paraná; o Centro Vianei de Educação Popular e Associação dos Pequenos Agricultores do Oeste Catarinense (APACO) em Santa Catarina; o Centro de Apoio ao Pequeno Agricultor (CAPA) e o Centro de Tecnologias Alternativas e Populares (CETAP) no Rio Grande do Sul, entre outras.

As organizações que compõem a Rede identificam-se como construtoras de um "novo modelo de desenvolvimento rural" que priorize os pequenos e médios produtores familiares livremente associados no processo de produção, beneficiamento e comercialização; leve em conta o potencial de cada agroecossistema; regionalize as estruturas de beneficiamento e transformação dos produtos (REDE

5. A concepção de tecnologia alternativa que teria guiado o PTA, segundo Almeida (1989, p. 208), foi: "aquela que, atendendo aos interesses do pequeno produtor rural, reforça sua capacidade de resistência na terra, de melhorar sua organização, seu poder de enfrentamento das forças econômicas e políticas adversas, de melhorar seu padrão de vida e segurança econômica.” 
TA/SUL, 1997).

Ao analisar as ações deste conjunto de ONGs articuladas em uma rede, Brandenburg (2002) chama atenção para a importância do seu trabalho para sobrevivência dos agricultores e a reconstrução de sua relação com a natureza:

Essas organizações desenvolveram um serviço de assistência aos agricultores numa perspectiva política crítica à modernização da agricultura. Sob o ponto de vista técnico, resgatam-se práticas tradicionais e já conhecidas dos agricultores, visando compor um conjunto de estratégias que permitiriam a reprodução social dos agricultores no campo. A agricultura alternativa representa uma opção de sobrevivência para o agricultor familiar e significa a reconstrução de uma relação socioambiental cuja raiz tem origem na condição camponesa (BRANDENBURG, 2002, p. 2).

$\mathrm{Na}$ região do Alto Uruguai do Rio Grande do Sul, por exemplo, destacou-se a atuação principalmente do CETAP no assessoramento das organizações de agricultores. $\mathrm{O}$ CETAP, segundo é apontado pelo seu próprio jornal informativo, Agricultura Alternativa, surgiu para suprir as necessidades de "buscar alternativas concretas aos agricultores" em um momento de crise:

É neste contexto de graves consequências geradas pelo processo de modernização e investida do capitalismo no campo e pela necessidade de buscar alternativas concretas aos agricultores que os Movimentos Sociais, sindicatos e entidades ligadas ao meio rural passaram a discutir, em meados da década de 80 , a necessidade de se criar um órgão de pesquisa e assessoria aos pequenos produtores. [...] os Movimentos Sociais organizados, durante o I Encontro Estadual de Tecnologias Alternativas, ocorrido em Passo Fundo, de 23 a 25 de janeiro de 1986, decidem criar o CETAP - Centro de Tecnologias Alternativas Populares (AGRICULTURA ALTERNATIVA, 1991, p. 3).

Desde o seu surgimento, o CETAP tem por "função desenvolver atividades de resgate, experimentação e difusão de Tecnologias Alternativas que fortaleçam a pequena produção e preservem o meio ambiente" (AGRICULTURA ALTERNATIVA, 1991, p. 3). O CETAP esteve no centro dos debates e da construção de experiências práticas relacionados à temática $d a$ agricultura alternativa ou ecológica, desenvolvida pelo sindicalismo rural da CUT, pelo Movimento dos Trabalhadores Rurais Sem-Terra (MST), pelo Movimento dos Atingidos por Barragens (MAB) e pelo Movimento de Mulheres Trabalhadoras Rurais (MMTR) na região.

O sindicalismo rural da CUT tem sua origem articulada com o surgimento dos outros movimentos sociais do campo no final dos anos de 1970 e no início da década de 1980 (como MST, MAB e MMTR, que nasceram no mesmo caldo cultural). Nos três estados do Sul, teve início com a formação de oposições sindicais aos sindicatos municipais ligados às Federações Estaduais dos Trabalhadores na Agricultura (FETAG-RS, FETAEP e FETAESC). Em alguns municípios em que os pequenos agricultores enfrentavam fortes dificuldades relacionadas a preços baixos de produtos agrícolas, falta de terras para as novas gerações, 
situações de agricultores que seriam atingidos por obras de barragens, entre outras, surgiu um movimento contestador das linhas políticas assumidas pelo sindicalismo e das diretorias dos sindicatos. Conformou-se uma concorrência em torno do sindicalismo, um "campo político" (BOURDIEU, 2007) onde os agentes desafiantes, que se articulavam nas chamadas oposições sindicais; acusavam as direções estabelecidas de serem acomodadas frente aos problemas dos agricultores; de serem antidemocráticas por centrarem-se nas figuras dos presidentes, sem haver mecanismos de discussão com as bases sobre os seus problemas com a ação sindical; de serem órgãos assistencialistas ligados aos governos para prestação de serviços de saúde, previdência, entre outras críticas. Além disso, alguns sindicatos e as próprias Federações eram acusados de serem corresponsáveis pelos problemas causados pelas políticas de modernização da agricultura e que afetavam os pequenos agricultores naquele momento, na medida em que as Federações e seus sindicatos haviam apoiado e/ou continuavam apoiando as políticas de modernização, mantendo relações próximas com os governos. As oposições sindicais, que viriam a formar a CUT rural, combatiam esse tipo de postura e argumentavam que queriam constituir um novo sindicalismo surgido dos interesses coletivos dos agricultores, “um sindicalismo 'autêntico', 'combativo', capaz de representar efetivamente as 'bases"' (SCHMITT, 1996, p. 193).

A conquista dos primeiros sindicatos pelas oposições se deu no início da década de 1980, nas regiões do Alto Uruguai do RS, Oeste de Santa Catarina e Sudoeste do Paraná, regiões próximas entre os três estados. Com novas conquistas de sindicatos e aproximação de outros considerados mais atuantes, foi se formando um movimento de renovação do sindicalismo em outras regiões dos estados, gerando tencionamentos e disputas dentro da estrutura sindical das Federações oficiais. Este movimento de renovação sindical seria chamado de Articulação Sindical Sul a partir de 1984. Após tentativas frustradas de conquistar as direções das Federações, os cutistas decidem formar uma estrutura organizativa paralela nos estados com a formação dos Departamentos Estaduais de Trabalhadores Rurais (DETRs) no final da década de 1980, seguindo uma orientação nacional da CUT que, em 1988, já tinha formado o seu Departamento Nacional de Trabalhadores Rurais (DNTR).

Desde a sua origem, em meados dos anos de 1980, alguns sindicatos cutistas já procuravam tratar não apenas de reivindicações dos agricultores, mas também problematizar questões relacionadas à produção e às tecnologias usadas na agricultura (alternativas produtivas). Como aponta Almeida:

No Rio Grande do Sul, alguns sindicatos de trabalhadores rurais localizados na região do Alto Uruguai (norte do Estado), iniciaram a discussão sobre a questão tecnológica, colocando o problema da inadequação da pesquisa agrícola, da assistência técnica e da extensão rural, inadequadas que são aos pequenos agricultores e voltadas especialmente para os "produtos de exportação". Juntamente com essa crítica, fazem a condenação da "agricultura insumista", ou seja, aquela que usa intensamente corretivos de solo, adubos e agrotóxicos, encarecendo o custo de produção e poluindo o meio ambiente (1989, p. 204-205). 
Essa posição mais genérica e difusa de condenação da agricultura insumista pelo sindicalismo foi aprofundada a partir do início da década de 1990. Com a realização do II Congresso estadual DETR-RS, em 1993, foi tomada a decisão política de partir para uma etapa de organização da produção e de formulação de um projeto para o campo com base "no resultado das experiências concretas vivenciadas pelos trabalhadores desde a base e da reflexão política articulada do conjunto da CUT e de seu campo de alianças" (DETR-RS, 1993, p. 11). Com a formulação deste projeto para o campo, pretendia partir para uma tática de ação sindical não mais somente de "caráter reivindicatório e contestatório” (id.), mas tratava-se de elaborar uma "proposta alternativa de desenvolvimento rural" que servisse para "definição de pautas concretas de reivindicação e negociação" (id.). Este novo modelo de agricultura a ser construído, além de ter por metas fortalecer os agricultores familiares e apoiar a reforma agrária, implicava fazer escolhas tecnológicas que levassem em conta preocupações ecológicas e culturais. Nas resoluções do II Congresso, já eram apresentados alguns indicativos do que seria esse projeto que passaria a embasar o seu projeto:

Um Projeto Alternativo de Desenvolvimento que garanta a viabilização da Agricultura Familiar implica em: a) um novo modelo tecnológico que leve em conta as questões sociais e ecológicas da produção agrícola; b) novas formas de organização da produção, comercialização, beneficia- mento da produção e abastecimento; c) reforma agrária enquanto instrumento para transformação do atual modelo de desenvolvimento da agricultura brasileira; d) política agrícola diferenciada para o pequeno agricultor; e) pesquisa e extensão rural voltados para o interesse dos trabalhadores; f) construir as bases culturais de um desenvolvimento alternativo, resgatando valores como a solidariedade, a cooperação e estabelecendo uma nova relação homem-natureza (DETR-RS, 1993, p. 14-17, grifos nossos, ELP) ${ }^{6}$.

Com a decisão de unificar o sindicalismo rural brasileiro, por intermédio da entrada do DNTR na estrutura da CONTAG (e os DETRs dos Estados nas FETAGs) e a filiação da Confederação à CUT, em 1995, esta proposta de construção de projeto alternativo de desenvolvimento rural, que vinha sendo construída no interior do sindicalismo cutista, passou a ser adotada pelo conjunto do sindicalismo dos trabalhadores rurais em nível nacional. Acompanhando estas mudanças na estrutura do sindicalismo rural brasileiro também ocorreu a emergência de uma nova categoria de identificação, que passou a unificar boa parte do sindicalismo: a agricultura familiar.

Para Medeiros (2001) e Picolotto (2011), a afirmação da identidade de agricultor familiar como unificadora de boa parte do sindicalismo relaciona-se a uma série de fatores: ao aumento da importância dos pequenos produtores no interior do sindicalismo, que vinha ocorrendo desde a década de 1980; à reivindicação destes

6. Este debate de construção de um Projeto Alternativo de Desenvolvimento também ocorria neste mesmo período no Fórum Sul dos DETRs (que abrangia o sindicalismo rural cutista dos três Estados do Sul) e em nível nacional no DNTR/CUT. Maiores detalhes sobre este debate ver Picolotto (2011). 
agricultores por um novo modelo de desenvolvimento; ao aumento do debate intelectual sobre a temática; às atividades de formação e intercâmbios com países europeus, visando conhecer suas experiências (promovidas pela Igreja e por ONGs europeias); à realização das grandes mobilizações nacionais chamadas de Gritos da Terra Brasil, a partir de 1994; e à criação de políticas públicas específicas, como o Programa Nacional de Fortalecimento da Agricultura Familiar (PRONAF), em 1996.

\section{O SINDICALISMO DA AGRICULTURA FAMILIAR E A PAUTA AMBIENTAL}

Na região Sul, com a adoção da categoria de identificação agricultura familiar e com a conquista do PRONAF, ocorreu um processo de (re)organização e fortalecimento dos atores da agricultura familiar e de novo rompimento com a estrutura sindical da CONTAG na região. No Estado de Santa Catarina, devido a dificuldades dos cutistas trabalharem em conjunto com a federação sindical, vinculada ao sistema CONTAG (FETAESC), eles decidiram criar uma organização própria, com a fundação da Federação dos Trabalhadores na Agricultura Familiar do Estado de Santa Catarina (FETRAFESC), em 1997, como representante específica dos sindicatos de agricultores familiares no estado. A FETRAFESC solicitou filiação à CONTAG, mas não foi aceita. Seguindo esta experiência autônoma, considerada exitosa, e o relativo fortalecimento que a identidade política da agricultura familiar tinha alcançado, o sindicalismo rural da CUT, na região Sul, decidiu criar, em 1999, a Frente Sul da Agricultura Familiar, como uma organização promotora da agricultura familiar na região, que congregava sindi- catos, cooperativas e ONGs). Dando sequência a esse processo de organização, foi fundada, em 2001, a Federação dos Trabalhadores na Agricultura Familiar da Região Sul (FETRAF-Sul), como uma organização sindical específica de agricultores familiares (RODRIGUES, 2004; PICOLOTTO, 2011). Essa proposta de um sindicalismo exclusivo de agricultores familiares foi nacionalizada, em 2005, com a criação da FETRAF-Brasil.

Da articulação dos esforços das organizações de agricultores, setores de Igrejas e ONGs em prol de um novo modelo de desenvolvimento rural, foi formado um movimento para promover a valorização da agricultura familiar e a gestação de formas de produzir mais autônomas dos agricultores na região Sul. Como afirma Melucci, os movimentos sociais são como "profetas do presente", "anunciam aquilo que está se formando sem que ainda disso esteja clara a direção e lúcida a consciência" (2001, p. 21). Nesse sentido, a identidade da agricultura familiar dava unidade a este conjunto diverso de atores, ao mesmo tempo em que possibilitava projetar um objetivo comum (uma utopia), que era a busca do reconhecimento da sua importância socioeconômica por meio do fortalecimento da sua identidade social, da organização política e da construção de um projeto alternativo de desenvolvimento rural.

Desde a fundação desta nova organização sindical, a dimensão ambiental aparece com força em seu programa político. Primeiramente, aparece associada de forma genérica ao tema da construção do projeto alternativo de desenvolvimento rural, herdado dos debates anteriores da CUT e da CONTAG. Neste sentido, nas resoluções do Congresso de fundação da Federação é destacado que um dos seus "principais eixos de atuação" seria: "responder 
adequadamente à problemática econômica da categoria, por meio de uma intervenção afirmativa na organização da produção, com base em princípios agroecológicos, desde o financiamento até a comercialização." (FETRAF-SUL, 2001, p.22).

Nos congressos seguintes seria mais detalhado como a Federação incorporaria o tema ambiental no seu projeto de agricultura. No I Congresso, realizado em 2004, foi definido que um de seus temas centrais de atuação seria: "avançar na organização socioeconômica da agricultura familiar como elemento fundamental para a implantação de um desenvolvimento sustentável e solidário" (FETRAF-SUL, 2004, p.29). Neste sentido, foram traçadas diretrizes para que o sindicalismo em conjunto com as organizações parceiras de crédito (como a Cooperativa de Crédito Rural com Interação Solidária - CRESOL), as cooperativas e associações de produção (que são diversas, de âmbito local nos municípios e regional), as redes de certificação solidária (como a Rede EcoVida que atua em toda a região Sul) e as ONGs de apoio conseguissem ter ações concretas para a realização do projeto de desenvolvimento da Federação, tais como: produção agroecológica, agroindustrialização familiar, comercialização direta e iniciativas de socioeconomia solidária. Para isso, seria preciso construir uma estratégia de "intervenção na organização da produção", com papéis claros e estabelecidos entre a "organização sindical", com papel político - coordenador geral e a "organização econômica" - da agricultura familiar que teriam papel de estimular e oferecer alternativas concretas de produção, segundo estes preceitos, aos agricultores.

No II Congresso, realizado em 2007, a Federação reafirmou as orientações do Con- gresso anterior, enfatizando que busca: construir a agroecologia como modelo de produção agropecuário; a transformação de produtos através das agroindústrias; a organização da comercialização através de canais institucionais (como o Programas de Aquisição de Alimentos da Agricultura Familiar - PAA), da comercialização direta e dos canais da economia solidária e do comércio justo; o estímulo à produção para autoconsumo das famílias, as atividades nãoagrícolas e a produção de sementes próprias como fontes de geração de rendas e de diminuição dos custos de produção, e, por fim, fazia uma recomendação para que a produção de ciência e tecnologia, realizada pelos centros de excelência, fosse orientada e adequada para a realidade dos agricultores familiares (FETRAFSUL, 2007).

O depoimento dos dirigentes da FETRAF-Sul também revelam a importância que a dimensão ambiental tem adquirido no seu projeto de agricultura. Altemir Tortelli, coordenador geral da FETRAF-Sul, entre 2004-2010, referindo-se à proposta de um novo modelo de desenvolvimento rural, afirma ser necessário:

Além de construir um sindicato forte, de construir um grande embate com o Estado, com os governos e avançar nas políticas públicas [...] nós também precisaríamos construir, na vida real, lá na comunidade, na propriedade, uma outra forma de pensar a produção, de pensar a relação do homem com a natureza, do homem com o meio, do homem e a família com a propriedade, com a terra, com os meios de produção, com o maquinário, com o mercado, com a transformação daquilo que nós produzimos. [...] Vamos produzir leite, sim, vamos melho- 
rar, vamos ter uma tecnologia alternativa, vamos produzir de forma agroecológica, vamos fazer equilíbrio ambiental, vamos respeitar a água, o solo, o ar. Mas vamos ter cooperativas que vão organizar essa produção, que organizar a transformação e que vão organizar o mercado. (Entrevista ao autor, 2010).

Como se percebe, o tema da agroecologia aparece como central na estratégia de organizar a produção desde a fundação da FETRAF (e mesmo antes, como mostrado na seção anterior), entretanto, muda de sentido ao longo dos anos.

Se nos primeiros anos de fundação da Federação a agroecologia tendia a ser entendida como uma técnica de produção, cujas orientações nesta área eram "reforçar os processos que objetivem o avanço de um novo modelo tecnológico que tenha por base a agroecologia e a soberania na qualidade das sementes, de forma articulada com a Rede EcoVida e com as entidades e organizações que atuam diretamente nesta perspectiva" (FETRAF-Sul, 2004, p.34).

Com o avançar do debate no interior da Federação, ela passou a ser entendida de uma forma ampla e conjugada intimamente com o projeto de agricultura familiar do sindicalismo. Uma definição mais ampla e elaborada aparece nas resoluções do III Congresso:

A FETRAF-SUL/CUT adota a agroecologia como base de um novo processo da agricultura familiar no sentido de construção de um novo modo de fazer e viver a agricultura. Não apenas como tecnologia sem a utilização de agrotóxicos, mas como nova concepção de agricultura, fundada em uma nova relação dos (as) agri- cultores (as) familiares com a terra, com a produção, com o ambiente e com a vida. Buscaremos, nos fundamentos da agroecologia, os princípios para adotar uma concepção de agricultura familiar pautada na diversificação e na policultura, associando a produção para autoconsumo. (FETRAF-SUL, 2007, p.57, grifos nossos, ELP).

O tema da construção de uma agricultura ecológica aparece normalmente contraposto ao do modelo da grande agricultura de exportação, do chamado agronegócio. Este modelo de exploração agropecuária é visto como causador de degradação ambiental, de dependência tecnológica e da exclusão social no campo. Por outro lado, a agricultura familiar é vista não somente como um espaço de produção agrícola. É um espaço de vida, que preserva as culturas locais e os recursos naturais, dinamiza as economias locais, etc. Esta oposição entre modelos fica evidente na passagem do II Congresso da FETRAF-Sul:

As ações do agronegócio se pautam pela especialização produtiva, pela monocultura voltada para a exportação, pela adoção de tecnologias de ponta e de produção em larga escala, pela dependência das tecnologias "modernas" (transgênicos, nanotecnologia) e numa visão predatória de "exploração" dos ecossistemas e dos recursos naturais. [...] A agricultura familiar pode ser considerada mais do que um espaço de produção agrícola e de dinamização das economias locais, mas, fundamentalmente, um espaço social de reprodução da vida rural, de revitalização das relações comunitárias e dos con- 
hecimentos tradicionais, de preservação do patrimônio cultural, de conservação da biodiversidade e dos recursos naturais, bem como de diversificação das estruturas socioorganizativas de base. (FETRAFSUL, 2007, p.41-42).

O depoimento de uma liderança da FETRAF na região do Alto Uruguai do RS também aponta a oposição de modelos de produzir entre as grandes empresas do agronegócio e a agricultura familiar:

Temos que abrir mais espaços para a produção orgânica, até por que a tendência agora e de que as pessoas cada vez mais valorizam a saúde, então pra mim hoje vai ter muito espaço no mercado hoje de produtos orgânicos pra se vender. Então a relação da agricultura familiar com a agroecologia, eu acho que nós vamos avançar mais ainda é no momento que nós conseguir produzir mais produtos orgânicos, ecológicos. Por que vai ser o diferencial, senão nós não vamos conseguir competir né... Se eu vou fazer um salame convencional, eu vou comprar da Sadia, da Perdigão, da Seara, de outras empresas, muda o que? Só se vender com preço mais barato né. Agora se eu produzir um produto diferenciado, colonial, orgânico, eu acho que daí vamos ter mercado, vai ter um mercado muito bom (Entrevista de Adir Lazzaretti ao autor, 2010).

O depoimento ressalta as diferentes qualidades de cada produto e o potencial que os produtos da agricultura familiar podem ter, desde que se diferenciem dos das grandes em- presas. Neste sentido, a forma de produzir da agricultura familiar se diferenciaria tanto por ser produzida de forma ambientalmente correta, quanto por resgatar positivamente elementos culturais do grupo social dos colonos. Neste sentido, a valorização dos produtos elaborados de maneira artesanal (segundo formas tradicionais de produzir, herdadas dos antepassados, os colonos) evidencia uma das formas de dar valores positivos para a agricultura familiar, para suas raízes e seus produtos típicos, que encontram mercados locais e regionais em consumidores que, muitas vezes, tem ou tiveram alguma relação com o meio rural e também valorizam ou passam a dar valor a estes produtos. Como destacado por Longhi e Santos (2003, p.8-9):

A importância que os consumidores têm dado aos chamados produtos coloniais deve-se, em grande parte, ao fato de uma parcela significativa da população urbana da maioria das cidades brasileiras mantém ainda um forte vínculo com o meio rural, considerando que o êxodo rural no Brasil iniciou a pouco tempo, comparando-se com outras regiões do mundo. Isso faz com que muitos costumes sejam preservados e também, através das feiras ecológicas, muitos hábitos alimentares vão sendo resgatados, ao contrário da artificialização e alienação consumista promovida pelos sistemas de comercialização mercantis. (grifo no original).

Neste sentido, a agroecologia é associada ao modelo de produção da agricultura familiar, resgatando e valorizando o saber fazer tradicional que a diferencia das grandes empresas do agronegócio. Seguindo estes preceitos, a Federação propõe, nas resoluções de seu III 
Congresso, de 2010, a agroecologia como "um novo modelo de fazer e viver na agricultura" ,que leve em conta os saberes tradicionais dos agricultores e a sua cultura local, que estimule a diversificação de atividades, a produção para autoconsumo das famílias e para o mercado, e que propicie maior autonomia aos agricultores nos processos produtivos frente às corporações transnacionais do setor agropecuário (FETRAFSUL, 2010).

Para além da construção da agroecologia, a Federação tem incluído em suas demandas recentes outros temas relacionados ao tema ambiental, tais como: reivindicação de pagamentos por serviços ambientais aos agricultores familiares que preservam áreas de matas, nascentes dos rios, recursos da biodiversidade etc.; ações de valorização dos conhecimentos tradicionais e das sementes crioulas; processo de regularização ambiental sem custo para os agricultores familiares; desenvolvimento de pesquisas que aprimorem a produtividades dos sistemas de produção da agricultura familiar de alimentos sadios e de qualidade com manejo sustentável dos recursos naturais; criação de uma política nacional de educação ambiental; realização de estudos sobre os impactos dos cultivos transgênicos sobre a biodiversidade e sobre a saúde humana; maior rigor na fiscalização sobre o uso dos agrotóxicos (FETRAF-SUL, 2010; 2011b).

Estas demandas visam fortalecer a agricultura familiar e o seu modelo de agricultura, associando-o com práticas de produção consideradas ambientalmente sustentáveis. Nos documentos da Federação, a agricultura familiar é apresentada como o setor social que pode constituir uma relação mais harmoniosa entre homem e natureza, produzir alimentos diversificados e com qualidade para o "povo brasileiro", e conjugar as intenções de desenvolvimento rural com o respeito à natureza $\mathrm{e}$ às culturas locais (FETRAF-SUL, 2004; 2007; 2010). Para a FETRAF, o agricultor familiar passa a ser o personagem que pode consolidar um novo modelo de desenvolvimento para a agropecuária brasileira, onde as preocupações com inclusão social, desenvolvimento agrícola e preservação das culturas locais e do ambiente constituem eixos centrais.

\section{CONSIDERAÇÕES FINAIS}

O tema ambiental não é novo no sindicalismo no Sul do Brasil. Desde a década de 1980, quando se construiu a crítica aos efeitos perversos da modernização da agricultura, já aparecia um esboço de uma pauta ambiental nas elaborações sindicais e das ONGs que colaboravam com o sindicalismo. Entretanto, foi com a elaboração do projeto alternativo de desenvolvimento rural em meados da década de 1990, que o tema ambiental ganhou contornos mais claros no projeto de agricultura dos cutistas e, depois, lavado para dentro da CONTAG. Com a elaboração deste projeto, o sindicalismo passaria por uma virada, deixaria de apenas criticar as consequências da modernização da agricultura e passaria a propor um novo modelo de organizar à produção nacional, sugerindo medidas de reforma agrária, política agrícola diferenciada para pequenos produtores, escolhas tecnológicas adequadas, estabelecimento de uma nova relação homem-natureza, entre outras.

Este debate sobre o projeto alternativo de desenvolvimento também guiou as elaborações iniciais da FETRAF-Sul sobre agricultura e sobre o ambiente. Com o passar dos anos, a 
Federação ampliou o debate interno e o tema ambiental acabou ganhando um novo relevo. Neste aspecto, as elaborações da Federação têm estabelecido um espaço importante para a construção da transição para um modelo de agricultura ecológica e têm incluído em suas pautas de reivindicação demandas relacionadas à busca pela preservação dos recursos naturais, pagamentos por serviços ambientais e ao incentivo da preservação de recursos e dos saberes tradicionais pelos agricultores familiares.

Para a FETRAF, da mesma forma, a construção da agroecologia passou a ser um conjunto de princípios gerais para pensar a adequação da agricultura familiar frente às preocupações ambientais contemporâneas. A agroecologia não é vista somente como um conjunto de técnicas de produção agropecuária, mas como base de uma nova concepção de agricultura, como um novo modelo de produzir e viver na agricultura, como base para gestionar os recursos naturais e ação do homem no meio. Neste sentido, a adoção da agricultura ecológica passa a dar um valor positivo para o projeto da agricultura familiar que a FETRAF constrói, associando-lhe o qualificativo da sustentabilidade ambiental.

Por fim, cabe ressaltar que mesmo que o tema ambiental tenha se mostrado fortemente presente no projeto político e na pauta do sindicalismo da FETRAF, ficaram algumas lacunas que não foi possível explorar neste trabalho. Neste sentido, cabem novos estudos para dimensionar qual influência real da presença de preocupações ambientais no programa geral do sindicalismo e a efetividade de sua concretização nas práticas das organizações de sua base, que atuam diretamente na produção e transformação dos produtos agropecuários, como as cooperativas, associações, agroindústrias, etc. e dos próprios agricultores familiares. É um campo de estudos que está aberto.

\section{REFERÊNCIAS BIBLIOGRÁFICAS}

AGRICULTURA ALTERNATIVA. CETAP, alternativa popular. Passo Fundo, v.1, n.2, 1991.

ALMEIDA, Joalcione. Propostas tecnológicas "alternativas" na agricultura. Cadernos de Difusão Tecnológica, n. 6(2/3), maio/dez, 1989.

ALONSO, A; COSTA, V.; MACIEL, D. Identidade e estratégia na formação do movimento ambientalista brasileiro. Novos estudos CEBRAP, n.79, nov. 2007.

BARCELLOS, Sérgio B. A formação do discurso da agroecologia no MST. Dissertação (Mestrado em Ciências Sociais), CPDA/UFRRJ, Rio de Janeiro, 2010.

BOURDIEU, Pierre. O poder simbólico. 10 ed. Rio de Janeiro: Bertrand Brasil, 2007.

BRANDENBURG, Alfio. Agricultura familiar, ONGs e desenvolvimento sustentável. Curitiba: Ed. UFPR, 1999.

BRANDENBURG, Alfio. Movimento Agroecológico: trajetória, contradições e perspectivas, Desenvolvimento e Meio Ambiente, $\mathrm{n}^{\circ}$ 6, jul./dez. 2002.

BRUM, Argemiro J. A Modernização da agricultura: trigo e soja. Petrópolis: Vozes, 1988.

CAPORAL, Francisco R.; COSTABEBER, J. A. Agroecologia e desenvolvimento rural sus- 
tentável: perspectivas para uma nova extensão rural. Revista Agroecologia e Desenvolvimento Rural Sustentável. v. 1, n. 1, jan./mar. 2000.

DELGADO, Guilherme. Questão agrária brasileira no pós-guerra e sua configuração contemporânea. Rio de Janeiro: IPEA, 2004.

DETR-RS. II Congresso Estadual: organizando a produção e construindo um novo sindicalismo. Passo Fundo, 1993.

DIAS, Marcelo M. As ONGs e a construção de alternativas para o desenvolvimento rural: um estudo a partir da Assessoria e Serviços a Projetos em Agricultura Alternativa (AS-PTA). Tese (Doutorado), CPDA/UFRRJ, Rio de Janeiro, 2004.

DIEGUES, A. C. Etnoconservação da natureza: enfoques alternativos. In: DIEGUES, A. C. (org.) Etnoconservação: novos rumos para a proteção da natureza dos trópicos. São Paulo: NAPAUB, 2000.

FETRAF-SUL. Resoluções do I Congresso Sindical da Agricultura Familiar. Chapecó, mar. 2001 (Congresso de fundação).

FETRAF-SUL. Resoluções do I Congresso da FETRAF-Sul/CUT. Chapecó, mar. 2004.

FETRAF-SUL. Resoluções do II Congresso da FETRAF-Sul/CUT. Francisco Beltrão, 2007.

FETRAF-SUL. Documento Base do III Congresso da FETRAF-Sul/CUT. Erechim, 2010.

FETRAF-SUL. Questões ambientais preocupam FETRAF-SUL/CUT. 2011a. Disponív- el em: <http://www.fetrafsul.org.br/2011/ index.php?option $=\quad$ com_content\&view $=$ article $\& i d=1405:$ questoes-ambientaispreocupam-fetraf-sulcut $\&$ catid $=1$ : ultimasnoticias\&Itemid $=104>$. Acesso em: 22 jan. 2012.

FETRAF-SUL. Agricultores familiares aprovam pauta para a Jornada Nacional de Lutas. 2011b. Disponível em: < http://www.fetrafsul. org.br/2011/index.php?option $=\% 20$ com_co ntent $\&$ view $=$ article $\&$ id $=533$ : agricultores-familiares-aprovam-pauta-para-a-jornada-nacional-de-lutas\&catid=3:destaques $>$. Acesso em: 24 jan. 2012.

GONÇALVES NETO, W. Estado e agricultura no Brasil. São Paulo: Hucitec, 1997.

LONGHI A.; SANTOS, M. S. O CETAP e a biodiversidade. Passo Fundo: CETAP, 2003. Disponível em: <http://cetap.org.br/wp-content/ uploads/2008/11/o-cetap-e-a-biodiversidade. pdf $>$. Acesso em: 15 mar. 2010.

MARTINE, G.; GARCIA, R. C. Impactos sociais da modernização da agrícola. São Paulo: Ed. Caetés, 1987.

MEDEIROS, Leonilde S. "Sem terra", “assentados", "agricultores familiares": considerações sobre os conflitos sociais e as formas de organização dos trabalhadores rurais brasileiros. In: GIARRACCA, N. (org.) ¿Una nueva ruralidad en América Latina? Buenos Aires: CLACSO, 2001.

MELUCCI, Alberto. A invenção do presente: movimentos sociais nas sociedades complexas. Petrópolis: Vozes, 2001. 
PICCIN, Marcos B. Lógicas socioculturais e estratégias produtivas no Assentamento Menina dos Olhos dos Sem-Terra. Dissertação (Mestrado), CPDA/UFRRJ, Rio de Janeiro, 2007.

PICOLOTTO. Everton L. As mãos que alimentam a nação: agricultura familiar, sindicalismo e política. Tese (Doutorado), CPDA/UFRRJ, Rio de Janeiro, 2011.

REDE TA/SUL. Interconectando ideias e ideais na construção da agricultura do futuro. In: ALMEIDA, Joalcione.; NAVARRO, Zander (org.) Reconstruindo a agricultura: ideias e ideais na perspectiva do desenvolvimento sustentável. Porto Alegre: Ed. UFRGS, 1997.

ROCHE, Jean. A colonização alemã e o Rio Grande do Sul. Porto Alegre: Globo, 1969 (v. 2).

RODRIGUES, A. S. A Federação dos Trabalhadores na Agricultura Familiar: um novo sindicalismo em construção. Dissertação (Mestrado), Programa de Pós-Graduação em Sociologia, UFPR, Curitiba, 2004.

SCHMITT Claudia J. Tecendo as redes de uma nova agricultura: um estudo socioambiental da região serrana do Rio Grande do Sul. Tese (Doutorado em Sociologia), UFRGS, Porto Alegre, 2001.

SCHMITT Claudia J. Transição para a agroecologia na Região Sul. In: Encontro Nacional de Agroecologia, Rio de Janeiro, 2002.

SCHMITT, Claudia J. A CUT dos colonos: história da construção de um novo sindicalismo no campo no Rio Grande do Sul. In: NAVAR-
RO, Z. (org.). Política, protesto e cidadania no campo. Porto Alegre: Editora da Universidade/ UFRGS, 1996.

SEVILLA GUZMÁN, Eduardo. Agroecología y desarrollo rural sustentable: una propuesta desde Latino América. XI Curso Intensivo em Agroecologia: Princípios y Técnicas Ecológicas Aplicads a la Agricultura. Rosario, 2000.

THOMPSON, Edward. P. A formação da classe operária inglesa: a árvore da liberdade. Rio de Janeiro: Paz e Terra, 1987 (v. 1).

THOMPSON, Edward. P. A miséria da teoria. Rio de Janeiro: Civilização Brasileira, 1981. 